1

2

3

4

5

6

7

8

9

10

11

12

13

14

15

17

18

19

20

21

22

\title{
Ag nanoparticles and wheat roots: a complex interplay
}

Ana.E Pradas del Real ${ }^{1,5^{*}}$, Vladimir Vidal ${ }^{2}$, Marie Carrière ${ }^{3,4}$ Hiram Castillo-Michel ${ }^{5}$, Clément Levard ${ }^{2}$, Perrine Chaurand ${ }^{2}$, Géraldine Sarret ${ }^{1}$

${ }^{1}$ ISTerre (Institut des Sciences de la Terre), Université Grenoble Alpes, CNRS, Grenoble, France.

${ }^{2}$ Aix-Marseille Université, CNRS, IRD, CEREGE UM34, 13545, Aix en Provence, France

${ }^{3}$ Univ. Grenoble-Alpes, INAC-SCIB, F-38000 Grenoble, France

${ }^{4} \mathrm{CEA}$, INAC-SCIB, F-38000 Grenoble, France

${ }^{5}$ ID21, ESRF-The European Synchrotron, CS40220, 38043 Grenoble Cedex 9, France

*ana.pradas@univ-grenoble-alpes.fr, ana-elena.pradas@esrf.fr

Graphical Abstract (TOC)

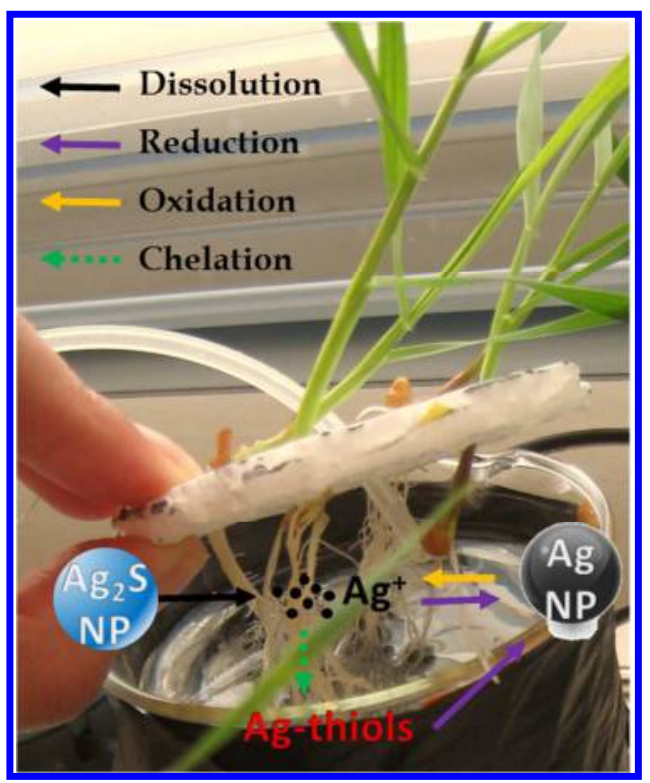

\section{ABSTRACT}

Agricultural soils are major sinks of silver nanoparticles in the environment, and crops are directly exposed to these emerging contaminants. A clear picture of their chemical transformations, uptake and transport mechanisms, and phytotoxic impacts is still lacking. In this work, wheat plants were exposed to pristine metallic (Ag-NPs) and sulfidized ( $\left.\mathrm{Ag}_{2} \mathrm{~S}-\mathrm{NPs}\right)$ silver nanoparticles and ionic $\mathrm{Ag}$. Data on Ag distribution and speciation, phytotoxicity markers and gene expression were studied. A multitechnique and multi-scale approach was applied combining innovating tools at both laboratory and synchrotron. Various chemical transformations were observed on the epidermis and inside roots, 
even for $\mathrm{Ag}_{2} \mathrm{~S}-\mathrm{NPs}$, leading to an exposure to multiple $\mathrm{Ag}$ forms, which likely evolve over time. Genes

27 involved in various functions including oxidative stress, defense against pathogens and metal

28 homeostasis were impacted in different ways depending on the Ag source. This study illustrates the

29 complexity of the toxicity pattern for plants exposed to Ag-NPs, the necessity of monitoring several

30 markers to accurately evaluate the toxicity, and the interest of interpreting the toxicity pattern in

31 light of the distribution and speciation of $\mathrm{Ag}$.

32

33

34 


\section{INTRODUCTION}

Agricultural soils are pointed as a major sink for engineered nanoparticles (NPs) due to the application of sewage sludge ${ }^{1}$, which contains various types of engineered nanomaterials (ENMS) and their secondary products ${ }^{2}$. Current regulations concerning sewage sludge application focus on their content of certain metals, none of them consider ENMS. The use of nanopesticides creates another, not precisely quantified, input of NPs in soils ${ }^{3}$. Silver nanoparticles (Ag-NPs) are one of the most prevalent metallic nanoparticles in consumer products due to their biocidal action ${ }^{4}$. Sulfidation is a major transformation of Ag-NPs that starts during the use of the products (e.g., laundry washing for textiles $)^{2}$ and is completed during wastewater treatment ${ }^{3}$, making silver sulfide $\left(\mathrm{Ag}_{2} \mathrm{~S}\right)$ the main $\mathrm{Ag}$ species in sewage sludge ${ }^{5}$. Due to the extremely low solubility of microcrystalline $\mathrm{Ag}_{2} \mathrm{~S}$, sulfidation has been considered as a natural antidote against Ag-NPs toxicity ${ }^{6}$. This opinion requires refinement since in sludges and soils $\mathrm{Ag}_{2} \mathrm{~S}$ precipitate in presence of other compounds (mostly organics) potentially forming nanometric and multiphasic Ag-S forms whose solubility is not known ${ }^{2}$. Moreover, a recent study evidenced the dissolution of $\mathrm{Ag}_{2} \mathrm{~S}$ NPs in aquatic media ${ }^{7}$.

Contrarily to other metals, natural $\mathrm{Ag}$ enrichments in soils are rare $^{8}$, so there is no known plant species, which has evolved to cope with Ag toxicity. The toxicity of Ag-NPs is supposed to be primarily due to the release of $\mathrm{Ag}+$ ions. Besides this, it could be a toxicity related with the characteristics of the nanoparticles (size, specific surface area, surface charge) that are not exerted by the bulk $\mathrm{Ag} .{ }^{9-11}$ As for other ENMs, the transfer of Ag-NPs inside plant tissues has been observed ${ }^{9,12}$, but it is difficult to conclude on their direct transfer since it could result from $\mathrm{Ag}^{+}$reduction inside plants. Various toxicity symptoms and up-regulation of genes linked with oxidative stress have been observed ${ }^{13}$. So far, most studies on the impact and transfer of Ag-NPs in plants have been done using pristine AgNPs. Recent opinions in nanoecotoxicology point the need of using environmentally realistic experimental conditions ${ }^{11}$, including the use of low doses (micromolar range or lower) ${ }^{11}$ and the study of aged NPs, i.e., $\mathrm{Ag}_{2} \mathrm{~S}-\mathrm{NPs}$. With only three published studies, data on transfer of $\mathrm{Ag}_{2} \mathrm{~S}-\mathrm{NPs}$ in 
60

61

62

63

64

65

66

67

68

69

70

71

72

73

74

75

76

77

78

79

80

81

82

plants and possible phytotoxicity is extremely scarce ${ }^{14-16}$. In a recent work, Wang et al. (2017) have found that $\mathrm{Ag}_{2} \mathrm{~S}-\mathrm{NPs}$ reduce the growth of cucumber and wheat plants, a process that seems to be related with an interference with the ethylene signaling pathway, the plant defense system and upward water transport ${ }^{16}$.

This study aimed at clarifying the changes in speciation of Ag-NPs and $\mathrm{Ag}_{2} \mathrm{~S}-\mathrm{NPs}$ in wheat and the uptake and transfer pathways, and at evaluating the phytotoxic impacts in light of Ag distribution and speciation. Wheat, a cereal used worldwide for food supply, was exposed to low doses, and a multitechnique and multi-scale approach was applied combining X-ray micro and nano-computed tomography ( $\mu$ and nano-CT), micro $X$-ray fluorescence ( $\mu$-XRF) and micro $X$-ray absorption spectroscopy ( $\mu$-XANES), toxicity markers and gene expression.

\section{MATHERIALS AND METHODS}

\subsection{Nanoparticles and chemicals}

Metallic silver nanoparticles (Ag-NPs) were provided by NanoAmor, Nanostructured and Amorphous Materials Inc. (USA). $\mathrm{Ag}_{2} \mathrm{~S}$ nanoparticles ( $\mathrm{Ag}_{2} \mathrm{~S}-\mathrm{NPs}$ ) were produced by the sulfidation of the Ag-NPs as stated in Levard et al. (2011) ${ }^{17}$ (detailed information is given in $\mathrm{SI}$ ).

Pristine and sulfidized nanoparticles (Ag-NPs and $\mathrm{Ag}_{2} \mathrm{~S} \mathrm{NPs}$ ) were thoroughly characterized in powder and in suspension (additional information is provided in $\mathrm{SI}$ ). $\mathrm{AgNO}_{3}$ powder was provided by SigmaAldrich 


\subsection{Plant culture}

Wheat (Triticum aestivum L.) plants were grown in hydroponics as described in SI. They were randomly selected to be treated as follow follow: i) control, no Ag addition; ii) $30 \mu \mathrm{M}$ Ag-NP; iii) 30 $\mu \mathrm{M} \mathrm{Ag} 2 \mathrm{~S}-\mathrm{NPs}$ and 4) $30 \mu \mathrm{M} \mathrm{AgNO}$.

Plants were harvested after 3 weeks of treatment. Roots and shoots were separated and thoroughly rinsed with ultrapure water and Ethylenediaminetetraacetic acid (EDTA) $20 \mathrm{mM}$ and fresh weights were recorded. Samples for phtytotoxicity studies were immediately frozen in liquid nitrogen and stored at $-80^{\circ} \mathrm{C}$ until analysis. Samples for synchrotron analysis and for X-ray computed-tomography were keep fresh until specific sample preparation.

\subsection{Silver distribution and speciation in roots cross sections (synchrotron $\mu$-XRF and $\mu$-XANES)}

Fresh roots were prepared for synchrotron analyses in cryogenic conditions as stated in Larue et al. $(2016){ }^{18} \cdot \mu$-XRF and Ag L LII-edge $\mu$-XANES measurements were performed on root thin cross sections (20-30 $\mu \mathrm{m})$ on the scanning X-ray microscope at ID21 beamline of the ESRF under cryo-conditions using a vibration-free cryo-stage, passively cooled by a liquid nitrogen dewar. Detectors included a $\mathrm{Si}_{3} \mathrm{~N}_{7}$ diode for $\mathrm{I}_{0}$ and a Silicon Drift Detector (X-flash Bruker $80 \mathrm{~mm}^{2}$ active area) for the emitted X-ray fluorescence. Focusing was realized using Kirkpatrick-Baez mirrors system. The photon flux was $3.07 \times 10^{10} \mathrm{ph} \cdot \mathrm{s}^{-1}$ at $3.45 \mathrm{keV}$ with a beam size of $0.4 \times 0.6 \mu \mathrm{m}$. $\mu$-XRF maps were recorded with various step sizes (from $0.3 \times 0.3 \mu \mathrm{m}^{2}$ to $4 \times 4 \mu \mathrm{m}^{2}$ ) with an incident energy of $3.45 \mathrm{keV}$, and a dwell time of $100 \mathrm{~ms}$. Elemental maps presented in this paper were obtained after fitting each pixel XRF spectrum using PyMCA software ${ }^{19}$ as described in Castillo-Michel et al. $(2016)^{20}$.

In the areas of interest identified in the $\mu$-XRF maps, Ag $L_{\| 11}$-edge $\mu$-XANES spectra were recorded by single point acquisition method (3.33 to $3.45 \mathrm{keV}$ energy range, $0.5 \mathrm{eV}$ step). When Ag aggregates were too small, the drift of the beam during acquisition did not allow to collect clean spectra. In 
107

108

109

110

111

112

113

114

115

116

117

118

119

120

121

122

these areas, $\mu$-XANES mapping was applied. In this case, regions of interest of 3-3.5 $\mu \mathrm{m} \times 4.5-5 \mu \mathrm{m}$ were scanned with a step size of $0.5 \mu \mathrm{m}$ at different energies across the $\mathrm{Ag} \mathrm{L}_{1 \| 1}$-edge. Maps were recorded in fluorescence mode in energy steps of $3 \mathrm{eV}$ from 3.32 to $3.34 \mathrm{keV} ; 0.5 \mathrm{eV}$ from 3.34 to 3.38 and $1 \mathrm{eV}$ from 3.34 to $3.40 \mathrm{keV}$. A stack of the obtained 107 XANES maps was performed with MATLAB routines (R2016, version 9.0) in order to get a $\mu$-XANES spectra for each $0.5 \times 0.5 \mu \mathrm{m}^{2}$ pixel of the examined area. $\mu$-XANES spectra were extracted by PyMCA software ${ }^{19}$. The possibility of averaging all the $\mu$-XANES spectra collected in the scanned area enables to get a good quality XANES spectra of small NP aggregates.

Bulk XANES spectra of reference compounds were recorded on unfocused mode during previous experiments ${ }^{21}$ in the same conditions as samples. Ag solid state reference compounds include $\mathrm{Ag}^{0}$ foil, $\mathrm{Ag}^{0}$ nanoparticles (Ag-NPs), $\mathrm{Ag}$ chloride $(\mathrm{AgCl}), \mathrm{Ag}$ nitrate $\left(\mathrm{AgNO}_{3}\right), \mathrm{Ag}$ phosphate $\left(\mathrm{Ag}_{3} \mathrm{PO}_{4}\right)$ and $\mathrm{Ag}$ carbonate $\left(\mathrm{Ag}_{2} \mathrm{CO}_{3}\right)$. Solution samples include Ag-malate $\left(10 \mathrm{mM} \mathrm{AgNO}_{3}\right.$ and $100 \mathrm{mM}$ malate, $\mathrm{pH}$ 5.5) and $\mathrm{Ag}-\mathrm{GSH}$ (10 mM AgNO 3 and $100 \mathrm{mM} \mathrm{GSH}, \mathrm{pH} 5.5$, prepared in anoxia). $30 \%$ glycerol was added to the solutions to avoid formation of ice crystals. Additionally, the spectra of the solid state $\mathrm{Ag}_{2} \mathrm{~S}-$ NPs and of Ag diethyldithiocarbamate $\left(\mathrm{C}_{5} \mathrm{H}_{10} \mathrm{AgNS}_{2}, \mathrm{Ag}\right.$-DEDTC) were recorded for this experiment.

$\mu$-XANES and XANES spectra were treated by using ATHENA software ${ }^{22}$. Principal components Analysis (PCA) and Target Transformations (TT) were used to identify the main Ag species preset in the samples. Then, their proportion in the samples was determined by Least-Squares Combination Fitting (LCF) of the experimental spectra. Details about these analysis are provided in SI.

\subsection{Silver concentrations}

Immediately after harvest, shoots and roots were separated, fresh weights were recorded and they were frozen in liquid $\mathrm{N}_{2}$ and lyophilized. After acid digestion $\mathrm{Ag}$ concentrations were determined by Inductively Coupled Plasma Mass Spectrometry ICP-MS (Elan DRC II Perkin Elmer). Further details are provided in SI. 
Before 3D imaging, fresh roots were soaked in successive ethanol solutions (from $30 \%$ to $100 \%$ vol) and dehydrated by critical point drying consisting in the replacement of ethanol by $\mathrm{CO}_{2}$ in the supercriticial state ${ }^{20}$.

3D imaging at the micro-scale $(\mu-\mathrm{CT})$ was performed with a Micro XCT-400 X-ray microscope (Zeiss XRadia) using various magnification achieving an isotropic voxel size from 2.9 to $0.62 \mu \mathrm{m}$ in a field of view of $1024 \times 1024 \times 1024$ voxels (3D pixels). Scans were acquired at $40 \mathrm{kV}$ and $250 \mu \mathrm{A}$. Between 1601 and 2501 projections were collected with an exposure time ranging from $4 \mathrm{~s}$ to 10 s per projection (depending on the magnification) through a $360^{\circ}$ rotation.

The roots were also scanned in 3D at the nano-scale using an UltraXRM-L200 3D X-ray microscope (Zeiss Xradia) equipped with a copper X-ray source (rotating anode) producing a polychromatic beam with a maximum intensity at energy of $8.048 \mathrm{keV}(\mathrm{Cu} \mathrm{K} \alpha-\mathrm{X}$ ray emission) and Fresnel zone plate providing a spatial resolution of $150 \mathrm{~nm}$. Scans were recorded phase contrast mode with 901 projections from -90 to $90^{\circ}$ with an angle step of $0.2^{\circ}$ and an exposure time of $60 \mathrm{~s}$ per projection giving a total scanning time of $17 \mathrm{~h}$. The field of view (FOV) was $65 \times 65 \times 65 \mu \mathrm{m}^{3}$ with an isotropic voxel of $63.5 \mathrm{~nm}$. The FOV position of the nano-CT scan was centered at region of interest previously identified by $\mu$-CT. Reconstruction of the 3D images was performed using a Zeiss XRadia software (XM Reconstructed-Parallel beam-9.0.6445 software) based on a filtered back projection algorithm.

Avizo 8.0 software was used for reconstructed dataset visualization.

As X-ray computed-tomography did not provide direct chemical and speciation information, 2D chemical mapping was performed on the same sample. The goal was to validate the identification of the Ag distribution in the samples by $\mu-\mathrm{CT}$ and nano-CT. $\mu$-XRF maps of the same roots and the same 
regions were recorded on ID21 as described above. In this case, measurements were not performed in cryogenic conditions and the photon flux was $3.1 \times 10^{10} \mathrm{ph} \cdot \mathrm{s}^{-1}$ at $3.45 \mathrm{keV}$.

\subsection{Phytotoxicity}

\subsubsection{Estimation of lipid peroxidation: malondialdehyde (MDA).}

Lipid peroxidation was evaluated on fresh tissues by the quantification of thiobarbituric acid reactive species (TBARS) by a modified method of Reilly and Aust as stated in Pradas del Real. $(2014)^{23}$. Additional information is provided in SI.

\subsubsection{Real-time polymerase chain reaction (RT-qPCR)}

Silver and other metals have been reported to impact the expression of genes involved in oxidative stress response, defense against pathogens, metal homeostasis, salt stress and plant growth ${ }^{24-26}$.

Quantitative analysis of the gene expression of selected genes was performed by reversetranscription real time PCR (RT-qPCR). Studied genes were selected to screen the potential interference of NPs with main plant vital processes: oxidative balance (catalase, iron superoxidose dismutase, glutathione peroxidase), homeostasis (Phosphoethanolamine N-methyltransferase), pathogen defense (Pathogen-inducible ethylene-responsive element-binding protein) and growth (ETTIN-like auxin response factor). The expression of the Metallothionein-like protein was also studied to shed light on NPs transport processes. Target-specific PCR primers for these genes were designed using Primer-BLAST ${ }^{27}$. Encoded genes names, accession number in NCBI database (National Center for Biotechnology: https://www.ncbi.nlm.nih.gov/) and the list of primers used are given in table S1. 
RNA was isolated from plant roots by using RNeasy Plant Mini Kit (Qiagen) according to manufacturer's instructions. RNA concentration and purity were assessed using a Nanodrop ND-1000 spectrophotometer (Thermo Fisher Scientific) by measuring absorbance at 230, 260 and $280 \mathrm{~nm}$. RNA was reverse transcripted into cDNA using the SuperScript II Reverse first strand kit (Invitrogen). Quantitative PCR was performed in a MX3005P multiplex quantitative PCR system (Stratagene) using MESA Blue qPCR Mastermix for SYBR Assay Low ROX (Eurogentec). We used the following thermal cycling steps: $95^{\circ} \mathrm{C}$ for $5 \mathrm{~min}$, then $95^{\circ} \mathrm{C}$ for $15 \mathrm{~s}, 55^{\circ} \mathrm{C}$ for $20 \mathrm{~s}$ and $72^{\circ} \mathrm{C}$ for $40 \mathrm{~s} 40$ times and finally $95^{\circ} \mathrm{C}$ for $1 \mathrm{~min}, 55^{\circ} \mathrm{C}$ for $30 \mathrm{~s}$ and $95^{\circ} \mathrm{C}$ for $30 \mathrm{~s}$ for the dissociation curve. PCR efficiencies were experimentally checked for compliance using a mix of all samples, with a quality criterion of $2 \pm 0.3$, and a theoretical value of 2 was used for calculations. Actin, 18sR and GAPDHR were chosen as housekeeping genes for normalization. Cq threshold was determined using the Mx-Pro 3.20 software (Stratagene) with default settings. mRNA expression analysis, normalization and statistical analysis were performed using the $\Delta \Delta \mathrm{Cq}$ method as described previously9. The RNA level modulation of selected genes was analyzed based on Ct comparison using REST 2009 (Qiagen). Data are expressed as percentages of the corresponding control \pm standard deviation.

\section{RESULTS AND DISCUSSION}

\subsection{Effect of initial Ag form on distribution and speciation within roots}

Distribution and speciation of $\mathrm{Ag}$ in roots were obtained by combining several highly complementary imaging tools (i.e. $\mu$-CT, nano-CT, $\mu$-XRF and $\mu$-XANES). $\mu$-CT provides the in-situ 3D distribution of dense voxels in intact samples and in relatively large field-of-views (FOV). Virtual cross-sections (various orientation or thickness) can be extracted from the obtained reconstructed volume. However, $\mu$-CT does not provide elemental information, to validate that dense voxels can be attributed to Ag accumulation regions, $\mu$-XRF mapping of the same FOV was performed. The good similarity in Ag-rich pixels (red pixels in Figure $1 \mathrm{~b}$ or purple pixels in Figure $5 \mathrm{~b}$ when $\mathrm{Ag}$ is co-localized 
with S) and dense voxels (brilliant voxels in Figure 1a and 5a) distribution contributes to validate the identification of $\mathrm{Ag}$ accumulation regions. $\mu$-CT is sensitive to accumulation regions with high local $\mathrm{Ag}$ concentration (i.e. such as Ag-NPs aggregates). However, it does not allow to discriminate Ag when it is homogeneously distributed in the plant matrix (i.e. single Ag-NPs or released Ag+). Recent technical developments allow performing 3D imaging with nanometer spatial resolution using X-ray laboratory sources (nano-CT). Coupling $\mu-\mathrm{CT}$ (spatial resolution at micrometer scale and relatively large FOV) with nano-CT (spatial resolution of $150 \mathrm{~nm}$ and small FOV) offers the opportunity to further study the Ag internalization processes. Synchrotron-based $\mu$-XRF provides $2 \mathrm{D}$ elemental information with high-sensitivity (low femtogram $\left./ \mu \mathrm{m}^{2}\right)^{20}$ and can be coupled (as in this study) to $\mu$ XANES spectroscopy to obtain speciation information.

The surface of plant roots exposed to $\mathrm{AgNO}_{3}\left(\mathrm{Ag}^{+}\right)$contained localized accumulation zones as shown by $\mu$-CT (Figure 1a and $1 \mathrm{~b}$, animations 1 and 2 in supporting information). These accumulation zones were not present in the control root (Figure S4.a and S5.a in SI). The 3D reconstructed image (Figure 1a) and the virtual cross sections (Figure $1 \mathrm{~b}$ and animation 2 in SI) showed that these accumulation zones had a variety of sizes (a few tens to $100 \mu \mathrm{m}$ in diameter). In contrast, $\mu$-XRF revealed an homogenous presence of $\mathrm{Ag}$ in root epidermal cells (Figure 1.b d). $\mu$-XRF analyses also revealed the presence of $\mathrm{Ag}$ in the cytoplasm of cortex cells, in the endodermis and in the central cylinder (Figure $\mathrm{S} 2$ in SI). Ag was also detected in intercellular spaces of the cortex, in accumulation regions of several microns in diameter (Figure 1.e).

The speciation of $\mathrm{Ag}$ at the cortex region was determined by $\mu$-XANES spectroscopy. In spot $1, \mathrm{Ag}$ was bound to thiol (84\%) and $\mathrm{O}$ ligands (modelled by $\left.\mathrm{AgNO}_{3}\right)(16 \%)\left(\mathrm{AgNO}_{3}\right.$-cortex 1 in Figure 2). Chelation by thiol ligands is a well-known detoxification mechanism inside cells, but thiol ligands are also present in the apoplast ${ }^{28-29}$. Given the high affinity of $\mathrm{Ag}(\mathrm{I})$ for thiols, the formation of $\mathrm{Ag}$-thiols in the extracellular compartment is not surprising. In spot 2, a slight oscillation on the spectra at 3670-3380 eV was indicative of the presence of metallic $\mathrm{Ag}$ as minor species. Thus, part of $\mathrm{Ag}(\mathrm{I})$ was 
reduced into $\mathrm{Ag}(0)$. The reduction of ionic $\mathrm{Ag}$ into $\mathrm{Ag}-\mathrm{NPs}$ in plants exposed to $\mathrm{AgNO}_{3}$ has been reported previously $\mathrm{y}^{30-31}$, and proposed as a green technology for the production of Ag-NPs ${ }^{17}$. In parallel, a significant Ag translocation from roots to shoots was measured (Figure S3.a). The presence of $\mathrm{Ag}$ both in the apo-and symplast and in the central cylinder suggests that both types of transport pathways, apo- and symplastic, are used by Ag ions.

For roots exposed to Ag-NPs, $\mu-\mathrm{CT}$ and $\mu$-XRF show the presence of localized Ag accumulation regions with a size of 1-4 $\mu \mathrm{m}$ adhering on the epidermis (Figure 4.a, d, e). Metallic Ag was the major Ag species of these accumulation regions (Figure. 2, root 3; Figure S4.e-f in SI, $80 \%$ and $97 \%$ respectively). At higher spatial resolution, nano-CT revealed that these Ag-NPs accumulated preferentially in discontinuities between root epidermal cells (Figure S5.b, c). In addition, root architecture and morphology were impacted since an absence of secondary roots and a proliferation of root hairs were observed exclusively for this treatment (Figure S5.a). Many Ag-NPs were fixed on root hairs (Figure 4. a, Animations 3 and 4 in supporting information, Figures S6.b and S7.b in SI).

A higher $\mathrm{Ag}$ root and shoot content was observed for this treatment compared to the $\mathrm{AgNO}_{3}$ treatment (Figure. S3), suggesting a nano-specific accumulation mechanism different to what was observed for the $\mathrm{AgNO}_{3}$ exposure. Our observations support two points of entry previously suggested in the literature. On one hand, high local concentration of metals in the epidermis was shown to cause rupture of this tissue ${ }^{32}$. Such ruptures in which Ag-NPs are preferentially accumulated (Figure S4.b, c) might facilitate the transfer of Ag inside roots. On the other hand, root hairs which have a thin cell wall, and take up nutrients by transport, diffusion, and endocytosis ${ }^{33}$ are considered as potential points of entry of NPs ${ }^{12}$.

In the epidermis Ag was mostly present as metallic $\mathrm{Ag}$ (root 3, Figure S4 in SI). However, a biotransformation of Ag was evidenced inside the roots where Ag was homogeneously distributed in the cell walls of the cortex (purple areas in Figure 4.d), as a mixture of Ag-thiol species and other 
ionic Ag species (86 and 14\% respectively, Figure S2, f). Contrary to what was observed in the epidermis, no $\operatorname{Ag}(0)$ was observed inside roots. Similar speciation results were observed in the cell walls of the endodermis (77 and $26 \%$ respectively, Figure $4 . c$ ). Thus, Ag-NPs were completely dissolved and complexed by organic ligands. Ag was detected inside cells of the cortex, in the endodermis and in the central cylinder. These observations suggest both apoplastic and symplastic transfer of $\mathrm{Ag}$ in monovalent form.

In the case of roots treated with $\mathrm{Ag}_{2} \mathrm{~S}-\mathrm{NPs}, \mu$-XRF shows that $\mathrm{Ag}$ is mainly colocalized with $\mathrm{S}$ (purple pixels in Figure $5 \mathrm{~b}$, resulting in mixing blue (S) and red $(\mathrm{Ag})) . \mu-\mathrm{CT}$ and nano-CT reveals that these $\mathrm{Ag}$ accumulation regions, with a size from 3 to $8 \mu \mathrm{m}$ are mostly on the root surface (Figure 5.a, c, b and 3D animations 5 and 6 in $\mathrm{SI}$ ). $\mu$-XANES showed that $\mathrm{Ag}$ at root surface was mainly present as $\mathrm{Ag}_{2} \mathrm{~S}$, with proportions ranging from $62 \%$ to $89 \%$ depending on the sample (Figure 2). Secondary Ag chemical forms were also identified, including metallic $\mathrm{Ag}$ (up to $40 \%$, arrows in Figure $5 \mathrm{e}$ ). In the secondary root (figure S4 in SI), no metallic Ag was found, but 13\% (point 2-2) to $26 \%$ (point 2-1) of $\mathrm{Ag}$ was bound to thiols. These results provide evidence that $\mathrm{Ag}_{2} \mathrm{~S}-\mathrm{NPs}$ were dissolved, and then $\mathrm{Ag}+$ ions were either complexed to thiol containing molecules or reduced to elemental Ag. These results contradict the general idea that $\mathrm{Ag}_{2} \mathrm{~S}$ is highly insoluble, which is based on the solubility constant of macrocrystalline $\mathrm{Ag}_{2} \mathrm{~S}\left(\mathrm{Ksp}=5.92 \cdot 10^{-51}{ }^{34}\right)$. The partial dissolution of $\mathrm{Ag}_{2} \mathrm{~S}$ could be favored by the root exudation $^{35}$. Wheat plants exudate organic acids and phytosiderophores, this process is enhanced in case of nutrient deficiency or metal stress ${ }^{36-38}$. In a recent study with Alfalfa plants exposed to $\mathrm{Ag}_{2} \mathrm{~S}$ NPs, the authors suggested that $\mathrm{Ag}_{2} \mathrm{~S}$ could be partially dissolved in the acidic environment of root border cells ${ }^{15}$. However, to our knowledge, this is the first work that clearly shows this process. Plants and plant extracts have been used to reduce $\mathrm{Ag}(\mathrm{I})$ to $\mathrm{Ag}(0)$ for the green synthesis of $\mathrm{Ag}-\mathrm{NPs}^{39}$, however this is the first time that the reduction of $\mathrm{Ag}_{2} \mathrm{~S}-\mathrm{NPs}$ is observed in the rhizosphere 
277 (endorhizosphere and rhizoplane in this case) of living plants. The identification of the reducing agent 278 would require further investigations.

$279 \mu$-XRF together with $\mu-C T$ showed that $\mathrm{Ag}_{2} \mathrm{~S}-\mathrm{NPs}$ were especially concentrated at the base of the lateral roots (Figure 5.a,d). During the development of lateral roots, the newly formed root breaks through the cortex and endodermis. Some authors suggest that this zone may provide a direct access for NPs to the xylem ${ }^{40}$. Nano-CT analysis were also performed in the base of lateral roots (data not shown), however the high disorder of cell layers made impossible the clear discrimination of internal and surface areas. A few Ag-rich spots were detected inside the root only by $\mu$-XRF (Figure 5.e, red arrows). Except these few internal $\mathrm{Ag}_{2} \mathrm{~S}$-rich spots, very low $\mathrm{Ag}$ signal was detected in the cell walls and cytoplasm of the cells by $\mu$-XRF (Figure S2 in SI) and no signal was detected in the endodermis and the central cylinder. This result is consistent with the low Ag root and shoot content measured for this treatment (Figure S3.a). Thus, despite a partial dissolution of $\mathrm{Ag}_{2} \mathrm{~S}-\mathrm{NPs}$ near roots, $\mathrm{Ag}$ transfer remained limited at the present exposition time.

\subsection{Phytotoxicity and gene expression response}

292

293

294

295

296

297

298

299

300

301
Both $\mathrm{Ag}$ uptake in roots and translocation in shoots increased in the order $\mathrm{Ag}_{2} \mathrm{~S}-\mathrm{NP}<\mathrm{AgNO}{ }_{3}<\mathrm{Ag}-\mathrm{NPs}$ exposure (Figure S3.a). Plant growth reduction was correlated with Ag accumulation in tissues with the highest effect observed in the Ag-NPs treatment (Figure S3. b). However, finer phytotoxicity markers and impacts on gene expression were specific for each Ag source. Previous studies showed that the phytotoxicity of Ag-NPs was associated with reactive oxygen species production and lipid peroxidation $^{13}$. However, no information is available about plants exposed to $\mathrm{Ag}_{2} \mathrm{~S}-\mathrm{NPs}$. Lipid peroxidation was evaluated by the quantification of thiobarbituric acid reactive substances (TBARS) (figure S3, c). It was the highest for the $\mathrm{AgNO}_{3}$ treatment, likely due to the high concentration in $\mathrm{Ag}^{+}$. Surprisingly, lipid peroxidation for the Ag-NPs and $\mathrm{Ag}_{2} \mathrm{~S}-\mathrm{NPs}$ treatments was lower than the control it was thus not correlated with growth reduction. 
302

303

304

As mentioned above, root architecture was impacted in the Ag-NPs treatment. Secondary roots did not develop and a proliferation of roots hairs was observed. The presence of Ag-NPs aggregates on root hairs might have an impact on their functions. Previous studies showed a loss or absence of root hairs for plants exposed to Ag-NPs, but this effect may be due to the high dose used ${ }^{12}$. Root hair proliferation is generally related with nutrient or water deficiency. The presence of Ag in the cell wall, as observed in our study (Figure 4.c, d), has been suggested to affect the function of nutrient transporter proteins ${ }^{13}$. In parallel, exposure to $\mathrm{Ag}_{2} \mathrm{~S}-\mathrm{NPs}$ and $\mathrm{AgNO}_{3}$ has been shown to down regulate the expression of aquaporins ${ }^{16}$. Exposure to Ag-NPs was not tested in this latter study so it could be related to root hair proliferation. Finally, changes in root architecture and morphology, are very likely to influence the entry of $\mathrm{Ag}$ in nanoparticulate and ionic form.

In order to further investigate the phytotoxicity induced by the different sources of $\mathrm{Ag}$, the expression of selected genes in the roots of wheat plants was studied by real-time polymerase chain reaction (RT-qPCR) (Figure 3). The genes encoding the enzymes catalase (CAT), superoxide dismutase (FeSOD) and glutathione peroxidase (GPX) were studied because of their key role in the oxidative stress. Each NP treatment induced changes in the expression of different genes. $\mathrm{Ag}_{2} \mathrm{~S}-\mathrm{NPs}$ lead to the overexpression of CAT and FeSOD whereas Ag-NPs induced a drop in the expression of FeSOD but an increase in that of GPX. Previous studies found up-regulated expression of CAT and SOD in Vigna radiata $^{24}$ and Arabidopsis thaliana ${ }^{25-26}$ exposed to pristine Ag-NPs. Taken together with the TBARS results and the localization and speciation of $\mathrm{Ag}$, our results suggest that plants exposed to Ag-NPs and $\mathrm{Ag}_{2} \mathrm{~S}$-NPs are able to control the oxidative stress by upregulating the enzymes related with radical scavenging, possibly due to the slow release of $\mathrm{Ag}^{+}$from the nanoparticles. Exposure to $\mathrm{AgNO}_{3}$, which induced a strong lipid peroxidation, did not induce any modulation of the expression of these genes. A possible explanation could be that the oxidative stress exceeds to capability of the enzymatic machinery, which is then not induced. 
We investigated the expression of the gene encoding metallothionein (Wali). Metallothioneins (MTs)

regulate metal homeostasis, and are also involved in the scavenging of reactive oxygen species

$328(\mathrm{ROS})^{41}$. Literature regarding the production of $\mathrm{MT}^{\prime}$ 's in plants exposed to Ag is scarce, with only one publication reporting the overexpression of $\mathrm{MT}$ in wheat plants exposed to $\mathrm{Ag}^{+}$and $\mathrm{Ag}-\mathrm{NPs}^{9}$. In the present study, however, we found overexpression of Wali for $\mathrm{AgNO}_{3}$ and $\mathrm{Ag}_{2} \mathrm{~S}-\mathrm{NPs}$ treatments while it was moderately but significantly down-regulated for the Ag-NPs treatment. It is suggested that the synthesis of MTs in plants could be related with the detoxification of sulfide (HS-), which is phytotoxic, although it has not been clearly demonstrated yet ${ }^{42}$. Since the speciation study evidenced some dissolution of $\mathrm{Ag}_{2} \mathrm{~S}-\mathrm{NPs}$, the overexpression of MT found for the $\mathrm{Ag}_{2} \mathrm{~S}-\mathrm{NPs}$ treatment may be a response to a release of $\mathrm{Ag}+$, but also of sulfide.

The three treatments also induced a down-regulation of the Phosphoethanolamine $\mathrm{N}$ methyltransferase (PEAMT), encoding a protein related with the salt stress, and an up-regulation of the Pathogen-inducible ethylene-responsive element-binding protein (PIEP), encoding a protein involved in the response to pathogens. Both results are opposite to that found for genes with similar functions in a previous study with $A$. thaliana ${ }^{25}$.

We also investigated the effect of the different treatments in the auxin-like response factor (ETT1). Auxins are hormones that control cell proliferation and growth in plants, and are involved in root branching. A crosstalk between ROS and auxin production in plant response to metal stress has been evidenced $^{43}$. In the present work, we did find an overexpression of the EET1 in the roots of $\mathrm{AgNO}_{3}$ treated plants but no impacts were found for the two NP treatments. Thus, the absence of root branching in the Ag-NPs treatment is not related to the expression of this gene.

\section{ENVIRONMENTAL IMPLICATIONS}

It has been generally hypothesized that Ag-NPs may act as "Trojan Horses" entering living organisms and then releasing $\mathrm{Ag}^{+}$over time causing toxicity ${ }^{44}$. This has been recently proposed as the 
351 mechanism by which $\mathrm{Ag}_{2} \mathrm{~S}-\mathrm{NPs}$ could be toxic to wheat and cowpea. In the present work, although

352 the Trojan horse scenario is very likely to take place, a more complex scheme was evidenced. As

353 illustrated in the synthetic Figure 6, interconversions of Ag forms outside and inside the plant, 354 leading to a mixture of Ag species, were observed. The distribution of Ag species probably evolves 355 over time, leading to a complex exposition pattern for plants, also exposed to $\mathrm{HS}^{-}$in the case of $\mathrm{Ag}_{2} \mathrm{~S}$ 356 NPs. The conflicting results usually seen in the literature concerning the toxicity of silver 357 nanoparticles are generally ascribed to differences in exposure conditions, structural properties of 358 nanoparticles and plant species. This evolving Ag speciation may represent an additional source of 359 variability and conflicting results.

Data from this study showed drastic different responses of the plant depending on the starting nanoparticles, highlighting the importance to include transformed nanoparticles in ecotoxicological studies.

Although the uptake and translocation of $\mathrm{Ag}$ was lower for the $\mathrm{Ag}_{2} \mathrm{~S}-\mathrm{NPs}$ exposure compared to the Ag-NPs exposure, phytotoxicity symptoms were observed. These results show that the sulfidation of Ag-NPs is not a perfect antidote to toxicity and that $\mathrm{Ag}_{2} \mathrm{~S}-\mathrm{NPs}$ are not as stable as expected when exposed to plant roots. In agricultural soils, the rhizospheric activity of plants might partly dissolve $\mathrm{Ag}_{2} \mathrm{~S}$ causing some impacts on crop quality and yield, and more generally on ecological services.

371 We thank the French program LabEx Serenade (11-LABX-0064) and has been carried out thanks to 372 the support of the A*MIDEX project « CREER » ( $n^{\circ}$ ANR-11-IDEX-0001-02). for providing a post doc 373 fellowship, CNRS (PEPS project NANOPLANTE) and EquipEx NanoID (ANR-10-EQPX-39) for funding 
thank the ESRF for providing PRC and "in house" beam time.

376

377

378

379

380

381

382

383

384

385

386

387

388

389

390

391

392

393

394

395

396

397

398

399

400

401

402

403

404

405

406

407

408

409

410

411

412

413

414

415

416

\section{REFERENCES}

1. Gottschalk, F.; Sonderer, T.; Scholz, R. W.; Nowack, B., Modeled environmental concentrations of engineered nanomaterials $\left(\mathrm{TiO}_{2}, \mathrm{ZnO}, \mathrm{Ag}, \mathrm{CNT}\right.$, fullerenes) for different regions. Environ. Sci. Technol. 2009, 43, 9216-9222.

2. Pradas del Real, A. E.; Castillo-Michel, H. A.; Kaegi, R.; Sinnet, B.; Magnin, V.; Findling, N.; Villanova, J.; Carriere, M.; Santaella, C.; Fernandez-Martinez, A., Fate of Ag-NPs in sewage sludge after application on agricultural soils. Environ. Sci. Technol. 2016.

3. Kah, M.; Hofmann, T., Nanopesticide research: current trends and future priorities. Environment International 2014, 63, 224-235.

4. Ma, X. M.; Geiser-Lee, J.; Deng, Y.; Kolmakov, A., Interactions between engineered nanoparticles (ENPs) and plants: Phytotoxicity, uptake and accumulation. Sci. Total Environ. 2010, 408 (16), 3053-3061.

5. Gottschalk, F.; Nowack, B., The release of engineered nanomaterials to the environment. Journal of Environmental Monitoring 2011, 13 (5), 1145-1155.

6. Levard, C.; Hotze, E. M.; Colman, B. P.; Dale, A. L.; Truong, L.; Yang, X. Y.; Bone, A. J.; Brown, G. E.; Tanguay, R. L.; Di Giulio, R. T.; Bernhardt, E. S.; Meyer, J. N.; Wiesner, M. R.; Lowry, G. V., Sulfidation of Silver Nanoparticles: Natural Antidote to Their Toxicity. Environ. Sci. Technol. 2013, 47 (23), 13440-13448.

7. Li, L.; Wang, Y.; Liu, Q.; Jiang, G., Rethinking Stability of Silver Sulfide Nanoparticles (Ag2SNPs) in the Aquatic Environment: Photoinduced Transformation of Ag2S-NPs in the Presence of Fe (III). Environ. Sci. Technol. 2015, 50 (1), 188-196.

8. Anjum, N. A.; Gill, S. S.; Duarte, A. C.; Pereira, E.; Ahmad, I., Silver nanoparticles in soil-plant systems. J. Nanopart. Res. 2013, 15 (9).

9. Dimkpa, C. O.; McLean, J. E.; Martineau, N.; Britt, D. W.; Haverkamp, R.; Anderson, A. J., Silver Nanoparticles Disrupt Wheat (Triticum aestivum L.) Growth in a Sand Matrix. Environ. Sci. Technol. 2013, 47 (2), 1082-1090.

10. Gubbins, E. J.; Batty, L. C.; Lead, J. R., Phytotoxicity of silver nanoparticles to Lemna minor L. Environ. Pollut. 2011, 159 (6), 1551-1559.

11. Holden, P. A.; Gardea-Torresdey, J.; Klaessig, F.; Turco, R. F.; Mortimer, M.; Hund-Rinke, K.; Cohen Hubal, E. A.; Avery, D.; Barcelo, D.; Behra, R.; Cohen, Y.; Deydier-Stephan, L.; Ferguson, P. L.; Fernandes, T. F.; Herr Harthorn, B.; Henderson, W. M.; Hoke, R. A.; Hristozov, D.; Johnston, J. M.; Kane, A. B.; Kapustka, L.; Keller, A. A.; Lenihan, H. S.; Lovell, W.; Murphy, C. J.; Nisbet, R. M.; Petersen, E. J.; Salinas, E. R.; Scheringer, M.; Sharma, M.; Speed, D. E.; Sultan, Y.; Westerhoff, P.; White, J. C.; Wiesner, M. R.; Wong, E. M.; Xing, B.; Steele Horan, M.; Godwin, H. A.; Nel, A. E., Considerations of Environmentally Relevant Test Conditions for Improved Evaluation of Ecological Hazards of Engineered Nanomaterials. Environ. Sci. Technol. 2016. 
12. Schwab, F.; Zhai, G.; Kern, M.; Turner, A.; Schnoor, J. L.; Wiesner, M. R., Barriers, pathways and processes for uptake, translocation and accumulation of nanomaterials in plants - Critical review. Nanotoxicoloav 2016, 10 (3), 257-278. López-Moreno, M. L.; Komárek, M.; Peralta-Videa, J. R.; Gardea-Torresdey, J. L., Exposure of engineered nanomaterials to plants: Insights into the physiological and biochemical responses-A review. Plant Physiology and Biochemistry 2016.

14. Wang, P.; Menzies, N. W.; Lombi, E.; Sekine, R.; Blamey, F. P. C.; Hernandez-Soriano, M. C.; Cheng, M.; Kappen, P.; Peijnenburg, W. J.; Tang, C., Silver sulfide nanoparticles ( $\left.\mathrm{Ag}_{2} \mathrm{~S}-\mathrm{NPs}\right)$ are taken up by plants and are phytotoxic. Nanotoxicologv 2015, (0), 1-9.

15. Stegemeier, J. P.; Schwab, F.; Colman, B. P.; Webb, S. M.; Newville, M.; Lanzirotti, A.; Winkler, C.; Wiesner, M. R.; Lowry, G. V., Speciation Matters: Bioavailability of Silver and Silver Sulfide Nanoparticles to Alfalfa (Medicago sativa). Environ. Sci. Technol. 2015, 49 (14), 8451-8460.

16. Wang, P.; Lombi, E.; Sun, S.; Scheckel, K. G.; Malysheva, A.; McKenna, B. A.; Menzies, N. W.; Zhao, F.-J.; Kopittke, P. M., Characterizing the uptake, accumulation and toxicity of silver sulfide nanoparticles in plants. Environmental Science: Nano 2017.

17. Levard, C.; Reinsch, B. C.; Michel, F. M.; Oumahi, C.; Lowry, G. V.; Brown, G. E., Sulfidation Processes of PVP-Coated Silver Nanoparticles in Aqueous Solution: Impact on Dissolution Rate. Environ. Sci. Technol. 2011, 45 (12), 5260-5266.

18. Larue, C.; Castillo-Michel, H.; Stein, R. J.; Fayard, B.; Pouyet, E.; Villanova, J.; Magnin, V.; del Real, A.-E. P.; Trcera, N.; Legros, S., Innovative combination of spectroscopic techniques to reveal nanoparticle fate in a crop plant. Spectrochimica Acta Part B: Atomic Spectroscopy 2016, 119, $17-24$.

19. Solé, V.; Papillon, E.; Cotte, M.; Walter, P.; Susini, J., A multiplatform code for the analysis of energy-dispersive X-ray fluorescence spectra. Spectrochimica Acta Part B: Atomic Spectroscopy 2007, $62(1), 63-68$.

20. Castillo-Michel, H. A.; Larue, C.; del Real, A. E. P.; Cotte, M.; Sarret, G., Practical review on the use of synchrotron based micro-and nano-X-ray fluorescence mapping and X-ray absorption spectroscopy to investigate the interactions between plants and engineered nanomaterials. Plant Physiology and Biochemistry 2016.

21. Larue, C.; Castillo-Michel, H.; Sobanska, S.; Cecillon, L.; Bureau, S.; Barthes, V.; Ouerdane, L.; Carriere, M.; Sarret, G., Foliar exposure of the crop Lactuca sativa to silver nanoparticles: Evidence for internalization and changes in Ag speciation. Journal of Hazardous Materials 2014, 264, 98-106.

22. Ravel, B.; Newville, M., ATHENA, ARTEMIS, HEPHAESTUS: data analysis for X-ray absorption spectroscopy using IFEFFIT. Journal of Synchrotron Radiation 2005, 12 (4), 537-541.

23. Pradas del Real, A.; García-Gonzalo, P.; Lobo, M.; Pérez-Sanz, A., Chromium speciation modifies root exudation in two genotypes of Silene vulgaris. Environmental and Experimental Botany 2014, 107, 1-6.

24. Nair, P. M. G.; Chung, I. M., Physiological and molecular level studies on the toxicity of silver nanoparticles in germinating seedlings of mung bean (Vigna radiata L.). Acta Physiologiae Plantarum 2015, 37 (1).

25. Kaveh, R.; Li, Y. S.; Ranjbar, S.; Tehrani, R.; Brueck, C. L.; Van Aken, B., Changes in Arabidopsis thaliana Gene Expression in Response to Silver Nanoparticles and Silver Ions. Environ. Sci. Technol. 2013, 47 (18), 10637-10644.

26. Syu, Y. Y.; Hung, J. H.; Chen, J. C.; Chuang, H. W., Impacts of size and shape of silver nanoparticles on Arabidopsis plant growth and gene expression. Plant Physiology and Biochemistry 2014, 83, 57-64.

27. Ye, J.; Coulouris, G.; Zaretskaya, I.; Cutcutache, I.; Rozen, S.; Madden, T. L., Primer-BLAST: a tool to design target-specific primers for polymerase chain reaction. BMC bioinformatics 2012, 13 (1), 134.

28. Yang, Y.; Zhang, F.; He, W.; Wang, X.; Zhang, L., Iron-mediated inhibition of H+-ATPase in plasma membrane vesicles isolated from wheat roots. Cellular and Molecular Life Sciences CMLS 2003, 60 (6), 1249-1257. 
29. Ferretti, M.; Destro, T.; Tosatto, S.; La Rocca, N.; Rascio, N.; Masi, A., Gamma-glutamyl transferase in the cell wall participates in extracellular glutathione salvage from the root apoplast. New Phvtologist 2009, 181 (1), 115-126.

30. Berumen, J. P.; Gallegos-Loya, E.; Esparza-Ponce, H.; Gonzalez-Valenzuela, R.; GonzalezValenzuela, C.; Duarte-Moller, A., XAS Study of silver nanoparticles formed in phaseolus vulgaris. 2009; $p$ 211-215.

31. Gardea-Torresdey, J. L.; Gomez, E.; Peralta-Videa, J. R.; Parsons, J. G.; Troiani, H.; JoseYacaman, M., Alfalfa sprouts: A natural source for the synthesis of silver nanoparticles. Langmuir 2003, 19 (4), 1357-1361.

32. Wang, P.; Menzies, N. W.; Lombi, E.; McKenna, B. A.; de Jonge, M. D.; Donner, E.; Blamey, F. P. C.; Ryan, C. G.; Paterson, D. J.; Howard, D. L., Quantitative determination of metal and metalloid spatial distribution in hydrated and fresh roots of cowpea using synchrotron-based X-ray fluorescence microscopy. Sci. Total Environ. 2013, 463, 131-139.

33. Ovečka, M.; Lang, I.; Baluška, F.; Ismail, A.; Illeš, P.; Lichtscheidl, I. K., Endocytosis and vesicle trafficking during tip growth of root hairs. Protoplasma 2005, 226 (1-2), 39-54.

34. Lide, D. R., CRC handbook of chemistry and physics. CRC press: 2004.

35. Hinsinger, P., Bioavailability of trace elements as related to root-induced chemical changes in the rhizosphere. Trace elements in the rhizosphere 2001, 25-41.

36. Li, Y.; Wang, L.; Yang, L.; Li, H., Dynamics of rhizosphere properties and antioxidative responses in wheat (Triticum aestivum L.) under cadmium stress. Ecotox. Environ. Safe. 2014, 102, 55-61.

37. Nian, H.; Yang, Z. M.; Ahn, S. J.; Cheng, Z. J.; Matsumoto, H., A comparative study on the aluminium- and copper-induced organic acid exudation from wheat roots. Physiologia Plantarum 2002, 116 (3), 328-335.

38. Oburger, E.; Gruber, B.; Schindlegger, Y.; Schenkeveld, W. D.; Hann, S.; Kraemer, S. M.; Wenzel, W. W.; Puschenreiter, M., Root exudation of phytosiderophores from soil-grown wheat. New Phvtologist 2014, 203 (4), 1161-1174.

39. Kumar, V.; Yadav, S. K., Plant-mediated synthesis of silver and gold nanoparticles and their applications. Journal of Chemical Technologv and Biotechnologv 2009, 84 (2), 151-157.

40. Dietz, K.-J.; Herth, S., Plant nanotoxicology. Trends in Plant Science 2011, 16 (11), 582-589.

41. Hassinen, V. H.; Tervahauta, A. I.; Schat, H.; Karenlampi, S. O., Plant metallothioneins - metal chelators with ROS scavenging activity? Plant Biology 2011, 13 (2), 225-232.

42. Lamers, L. P. M.; Govers, L. L.; Janssen, I. C.; Geurts, J. J.; Van der Welle, M. E.; Van Katwijk, M. M.; Van der Heide, T.; Roelofs, J. G.; Smolders, A. J., Sulfide as a soil phytotoxin - A review. Frontiers in Plant Science 2013, 4.

43. Yuan, H.-M.; Liu, W.-C.; Jin, Y.; Lu, Y.-T., Role of ROS and auxin in plant response to metalmediated stress. Plant signaling \& behavior 2013, 8 (7), e24671.

44. Lubick, N., Nanosilver toxicity: ions, nanoparticles or both? Environ. Sci. Technol. 2008, 42 (23), 8617-8617.

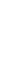



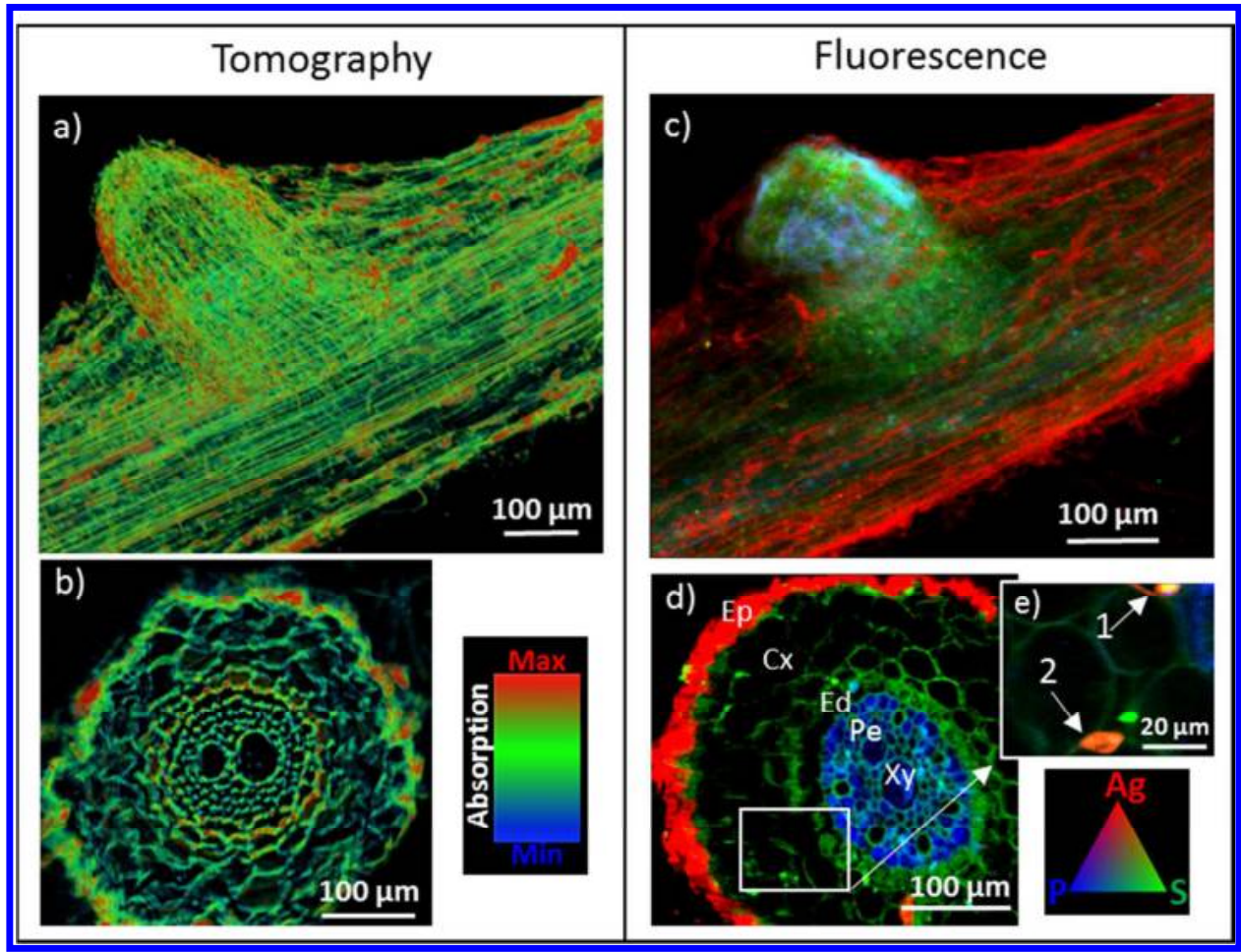

Figure 1. Roots of wheat plants exposed to $\mathrm{AgNO}_{3}$ : a) 3D reconstructed image by $\mu$-CT (voxel size 1 $\mu \mathrm{m}) \mathrm{b}$ ) virtual 2D slice ( $1 \mu \mathrm{m}$ thickness) extracted from a). $\mu$-XRF tricolor maps of entire root (1 px =1 $\mu \mathrm{m})(\mathrm{c})$, of cross section $(1 \mathrm{px}=1 \mu \mathrm{m})$ (Ep=epidermis, $\mathrm{Cx}=$ cortex, $\mathrm{Ed}=$ endodermis, Pe=pericycle, $\mathrm{Xy}=x y$ lem) (d) and of a zoom in the cortex (1 px =0.5 $\mu \mathrm{m})(\mathrm{e})$. Extremity of white arrows in e) indicate points where $\mu$-XANES spectra were collected. 


\section{Linear Combination Fitting (LCF)}

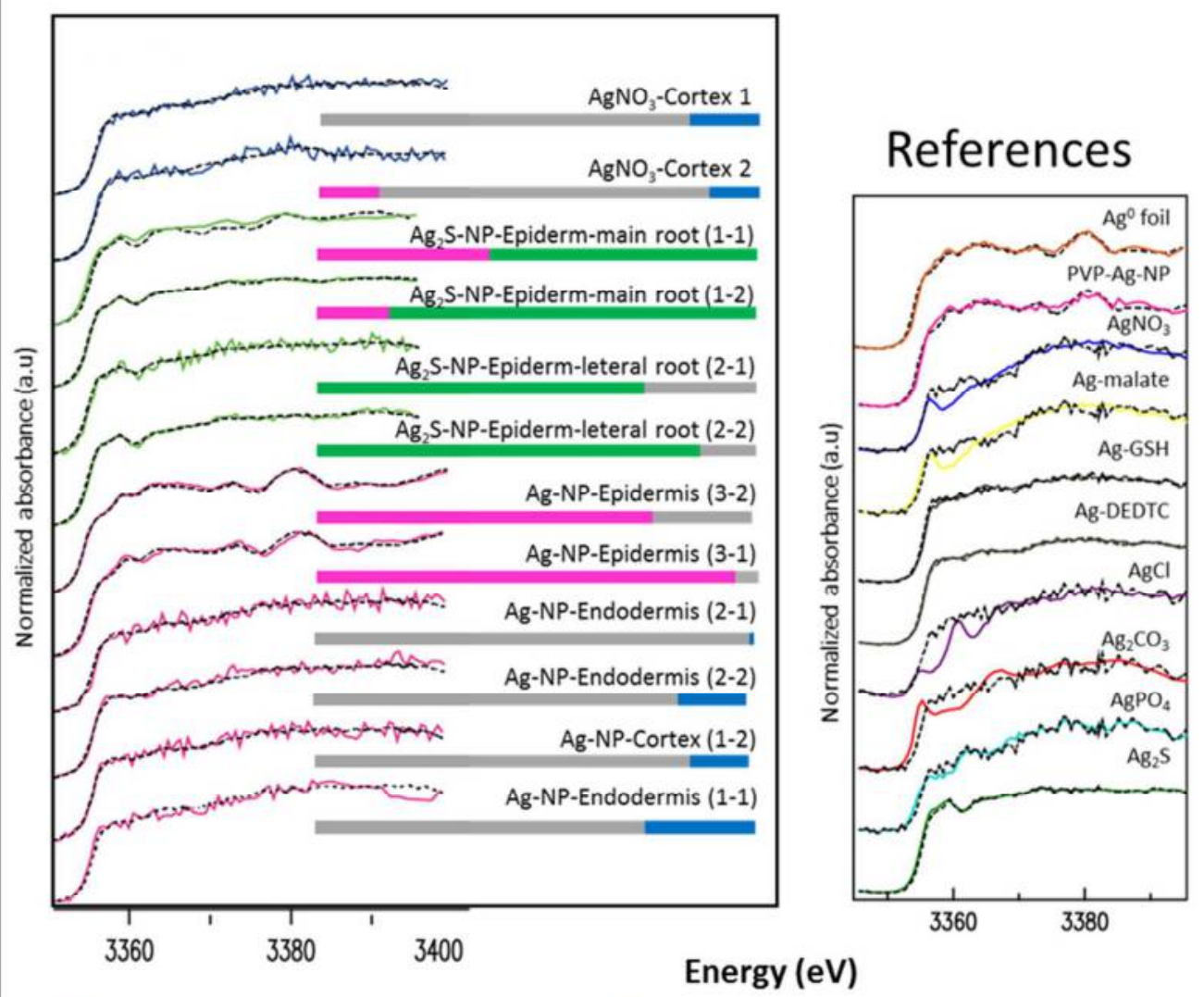

\section{$\mathrm{Ag}^{0} \square \mathrm{Ag}_{2} \mathrm{~S}-\mathrm{NPs} \square \mathrm{Ag}$-Thiol $\square \mathrm{AgNO}_{3}$}

Figure 2: Linear combination Fitting (LCF) of the $\mu$-XANES spectra collected in the different points of the samples (dotted lines), experimental spectra (soild lines). Results for the Linear Combination Fitting (LCF) of all samples are given in table S2 of SI. And Ag references used (solid lines) and reconstruction of these references by Target Transformation (dotted lines) for the three components determined by Principal Components Analysis (PCA). Reference of $\mathrm{AgNO}_{3}$ is a proxy for $\mathrm{Ag}^{+}$species ligated to $\mathrm{O}$ ligands. Ag-GSH (Ag-glutathione) and Ag-DEDTC (Ag- diethyldithiocarbamate) were indistinguishable and were used as proxy of Ag-Thiol. The spectra of AgO foil and Ag-NPs were also 


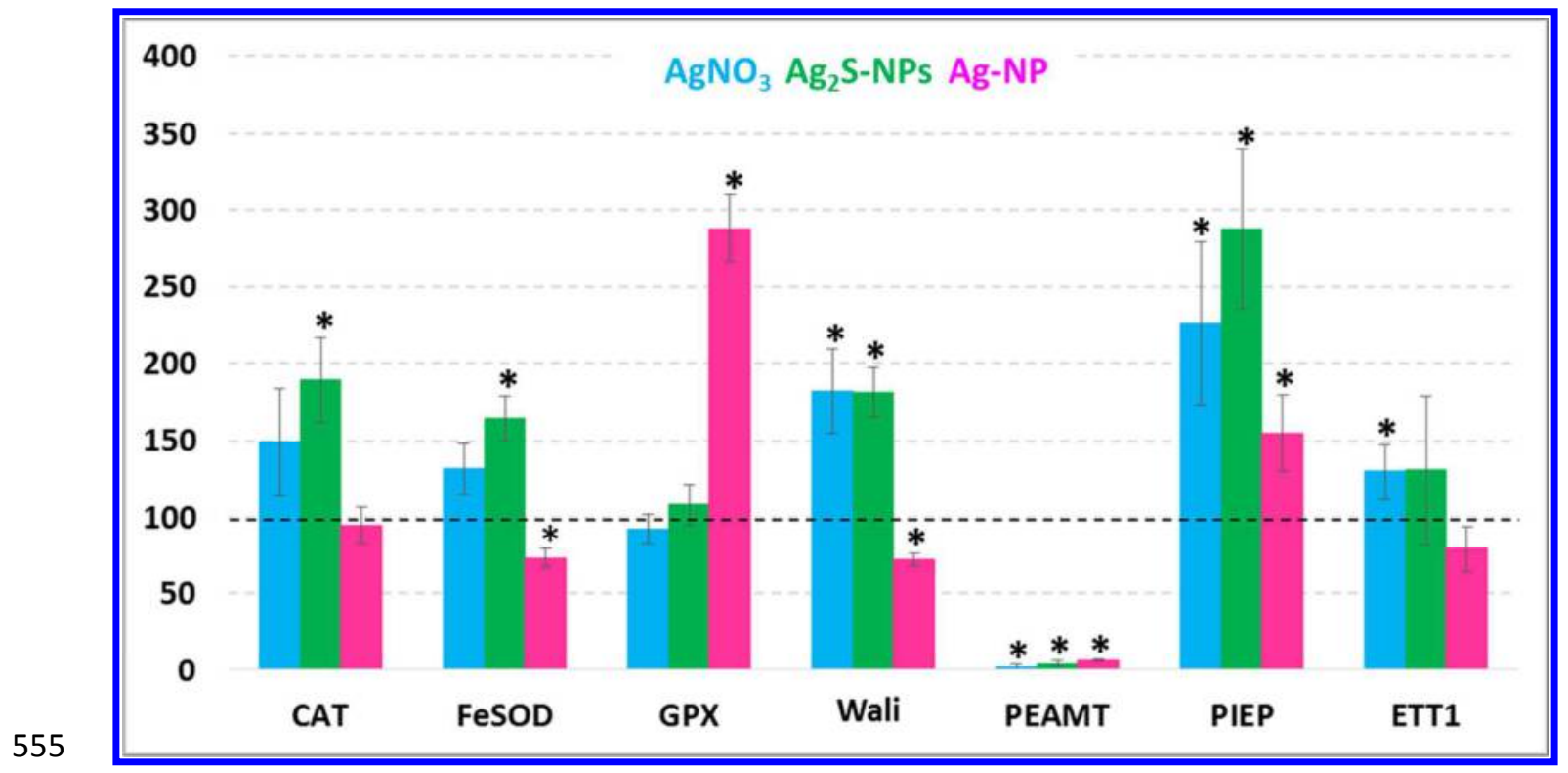

Figure 3. Gene expression quantified by qPCR in roots of plants exposed to $\mathrm{AgNO}_{3}$ (blue), $\mathrm{Ag}_{2} \mathrm{~S}-\mathrm{NPs}$ (green) and Ag-NPs (pink). Results are expressed as fold change regards control. They represent the average of 3 analytical replicates \pm standard deviation, $(* p<0.05)$. CAT (catalase), FeSOD (iron superoxidose dismutase), GPX (glutathione peroxidase), Wali (Metallothionein-like protein) PEAMP (Phosphoethanolamine N-methyltransferase), PIEP (Pathogen-inducible ethylene-responsive element-binding protein), ETT1 (ETTIN-like auxin response factor). 


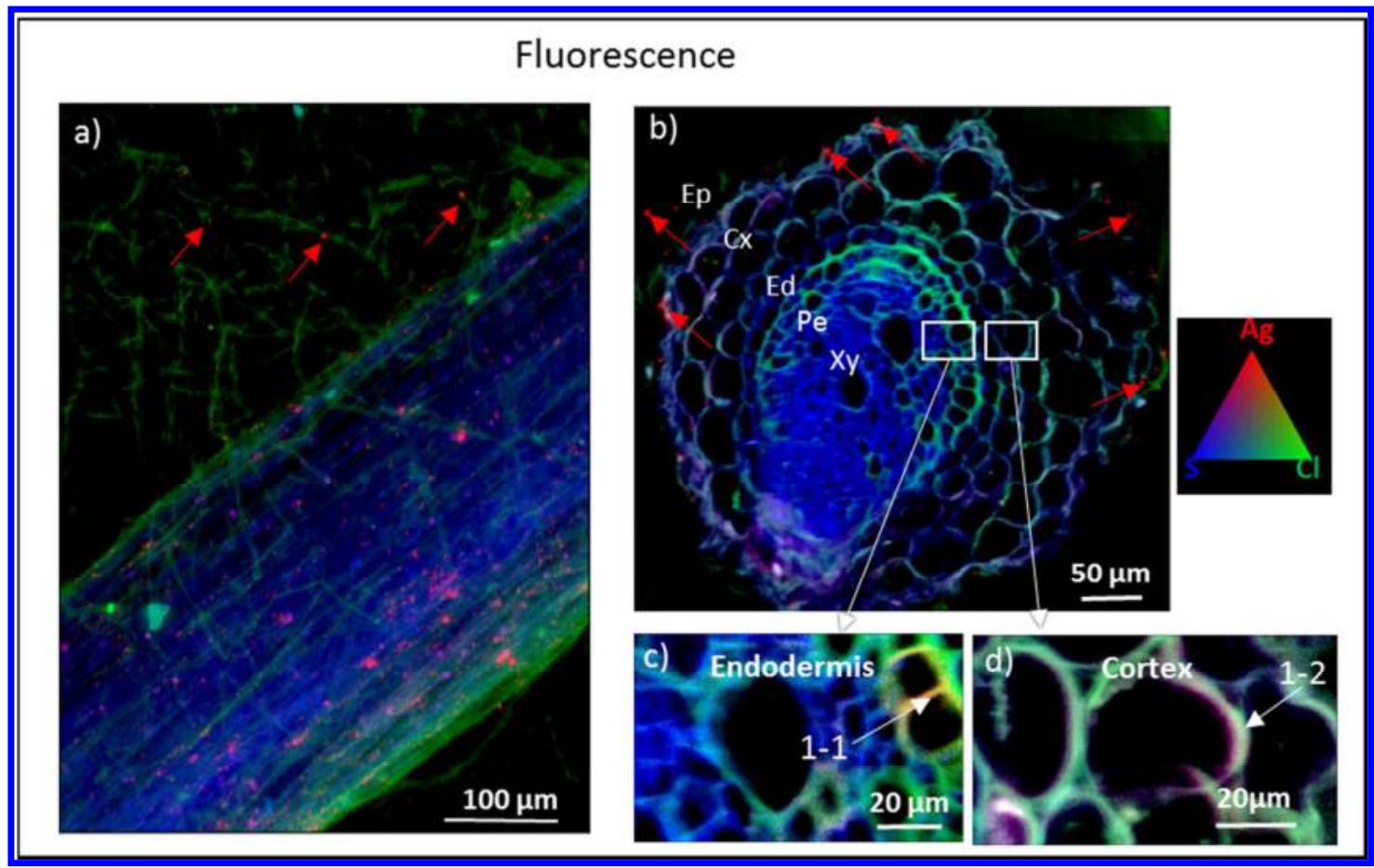

Figure 4. Roots of wheat plants exposed to Ag-NPs, $\mu$-XRF tricolor maps of a) entire root (1 px $=1 \mu \mathrm{m})$ $(1 \mathrm{px}=1 \mu \mathrm{m})$, (b) root cross section ( $\mathrm{Sf}=$ surface, Ep=epidermis, $\mathrm{Cx}=$ cortex, $E d=$ endodermis, $\mathrm{Pe}=$ pericycle, $\mathrm{Xy}=\mathrm{xylem})(\mathrm{b})$, and of a zoom in the endodermis (c) and cortex (d) $(1 \mathrm{px}=0.5 \mu \mathrm{m})$. Red arrows show preferential accumulation sites for Ag-NPs. Extremity of white arrows in c) and d) indicate points where $\mu$-XANES spectra were collected. 

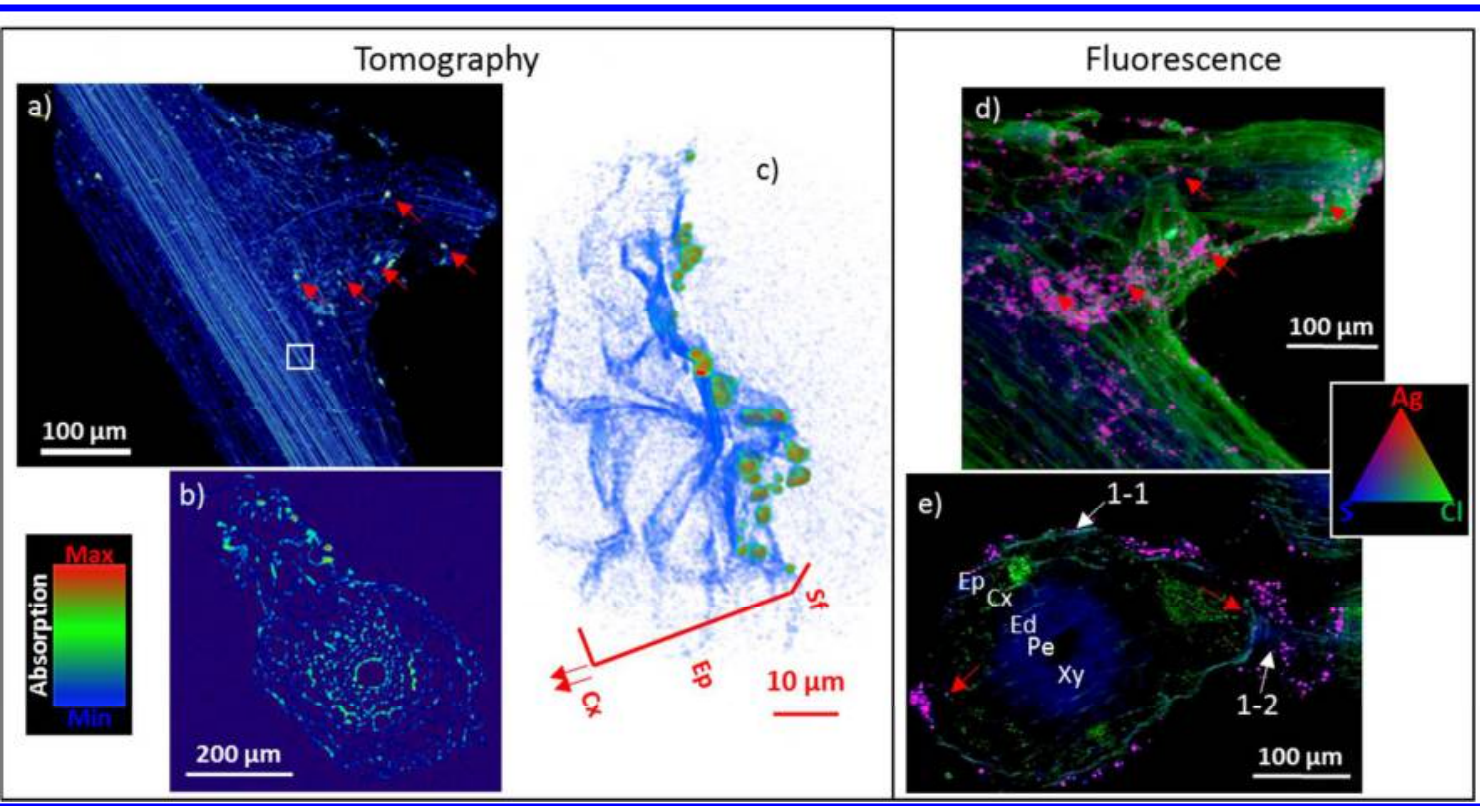

Figure 5. Roots of wheat plants exposed to $\mathrm{Ag}_{2} \mathrm{~S}-\mathrm{NPs}$ : a) 3D reconstructed image by $\mu-\mathrm{CT}$ (voxel size $0.9 \mu \mathrm{m}), \mathrm{b})$ virtual $\mu$-CT slice $(1 \mu \mathrm{m}$ thickness) extracted from a), c) nano-CT reconstructed image of the primary root surface (white square in a)) (voxel size of $63.5 \mathrm{~nm}$ ). $\mu$-XRF maps of entire root (1 px $=1 \mu \mathrm{m}) \mathrm{d}$ ), of a cross section (e) ( $\mathrm{S}=$ =surface, $E p=e$ idermis, $\mathrm{Cx}=$ cortex, $\mathrm{Ed}=$ endodermis, Pe=pericycle, $\mathrm{Xy}=\mathrm{xy}(\mathrm{em})$. Red arrows indicate equivalent $\mathrm{Ag}$ accumulation regions in images. White arrows in e) indicate points where $\mu$-XANES spectra were collected.

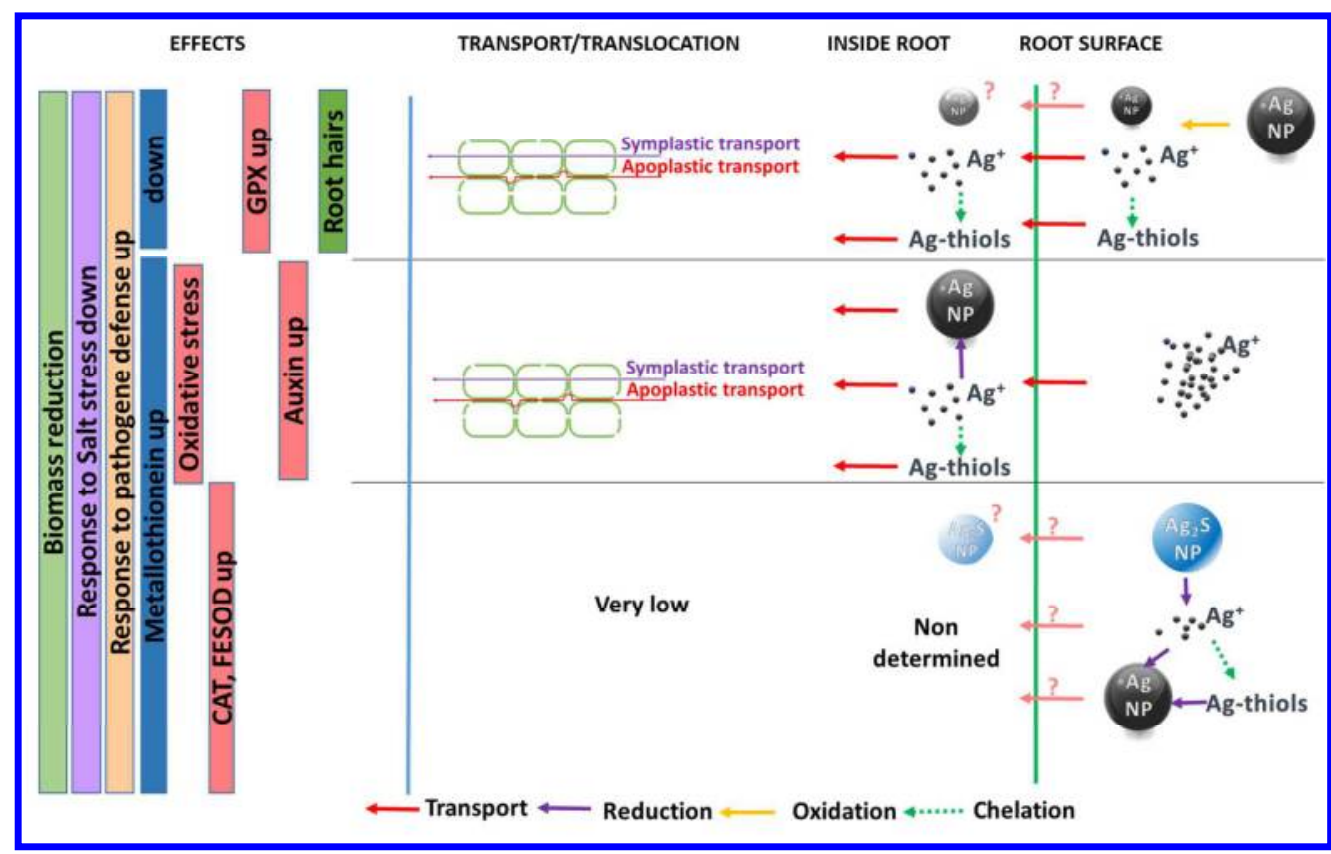

Figure 6. Synthesis of the observed changes in Ag speciation that take place inside and outside wheat roots depending on the starting materials, proposed transfer pathways and induced effects on plants. 